\title{
THE QUALITY OF SELECTED SOUTH AFRICAN AND INTERNATIONAL HOMOEOPATHIC MOTHER TINCTURES
}

\author{
Dr Mandé Michelle Scheepmaker ${ }^{1}$ and Dr Neil Travis Gower ${ }^{2 *}$ \\ ${ }^{1}$ Department of Homoeopathy, University of Johannesburg, Doornfontein Campus, PO Box 254 \\ Auckland Park 2006, South Africa, ${ }^{2}$ Department of Homoeopathy, University of Johannesburg, \\ Doornfontein Campus, PO Box 254 Auckland Park 2006, South Africa \\ *E-mail: neilg@uj.ac.za
}

\begin{abstract}
The high potential variability of chemical composition of the plant material involved in the manufacture of homoeopathic mother tinctures (a common source of homoeopathic medicines), renders both their quality control and assurance a significant challenge (Pande and Pathak, 2006). The absence of significant regulations regarding the quality of Complementary and Alternative Medicines (CAM) in South Africa contributes to this challenge (Gqaleni et al, 2007). In order to assess any quality differences between local and international manufacturers, the following homoeopathic mother tinctures, Artemisia absinthium, Rosmarinus officinalis e foliis recentibus, Salvia officinalis and Sambucus nigra, were chosen on the basis that they can be grown both locally in South Africa and internationally and are prepared according to the German Homoeopathic Pharmacopoeia (GHP), method 3a. Colour analysis was followed by thin layer chromatographic (TLC) analysis on each selected sample and relevant reference sample using both aluminum-backed TLC plates and glassbacked HPTLC plates. Photographs were taken of the resultant chromatograms, active components were identified, comparisons to the reference chromatograms were made and the overall quality of each homoeopathic mother tincture deduced. The quality of all nine of the selected samples manufactured internationally complied with the minimum quality standards set by the GHP. Five out of the six local samples complied with the minimum standards of the GHP._Notwithstanding the minimum GHP standards, the superior number of high quality international samples implies that their quality exceeded that of the locally manufactured tinctures. Greater regulation regarding the quality of these types of products has therefore been identified.
\end{abstract}

Keywords: Artemisia absinthium; Rosmarinus officinalis e foliis recentibus; Sambucus nigra; Salvia officinalis; thin layer chromatography; quality, homoeopathic, mother tincture, South Africa.

\section{Introduction}

During the past few decades, the use of homoeopathic preparations and herbal medicines in the developed world has become a popular and highly demanded form of medicinal treatment, which has been facilitated by less stringent regulations than other medications (WHO, 2009). As the international costs of mother tinctures have begun to escalate, due to various factors, the use of local manufacturers has become an imperative source option. A need therefore has arisen to regularly assess whether there is a difference in quality between locally and internationally manufactured mother tinctures and whether the quality of the local and international manufactured homoeopathic mother tinctures comply with the standard stipulated by the Homoeopathic Pharmacopoeia (Lee et al., 2007).

A mother tincture is a liquid preparation resulting from the extraction of a suitable source, namely plant or animal substance material with alcohol or water mixture within a specific ratio (Banerjee, 2002).

Many techniques have been used to determine the quality of mother tinctures, including most commonly thin layer chromatography (TLC) and mass spectroscopy, while high performance liquid chromatography allows for both the quantitative and qualitative analysis of substances (Waksmundzka-Hajnos et al., 2008). TLC allows for an affordable yet reliable and effective technique in the determination of the active components within a herbal product. Due to lack of quality regulation in South Africa, it is uncertain how many products comply with the intended quality levels stipulated in the various pharmacopoeiae. 
Through TLC analysis of selected homoeopathic mother tinctures, one is able to determine whether the active components of the samples are present and furthermore deduce whether the sample complies with the standard quality stipulated in the German Homoeopathic Pharmacopoeia and by implication, Good Manufacturing Practice (GMP).

\section{Material and Methods Research Samples}

Samples of the various homoeopathic mother tinctures were sourced from both local and international manufacturers and were all prepared according to the GHP, method 3a. In order to avoid bias no samples were procured from Natura Laboratories, Pretoria and all samples were repackaged and re-labeled by way of random allocation to a coding system by a dispensary assistant at the University of Johannesburg. All samples were decanted into identical unlabeled 50ml clear amber glass bottles and randomised by a research assistant according to a precise labelling coding system to ensure correct tracking of samples and to avoid bias.

\section{Colour Analysis}

$5 \mathrm{ml}$ of each sample of each mother tincture was measured and placed into a clear polytop and labeled. The samples were then visualized with the naked eye and the colour recorded. Pictures of each sample were taken with a Sony Cyber-shot DSC W300, set at 13 megapixels on manual exposure shooting, with no flash.

\section{Thin Layer Chromatography}

Reference chromatograms were developed using the active components stipulated for each mother tincture according to the German Homoeopathic Pharmacopoeia (GHP), or utilising a standardised reference sample verified to contain the active components (as for Artemisia absinthium). These reference chromatograms were then compared to the respective sample chromatograms, which were produced according to the methodology stipulated in the GHP. Other than the reference chromatogram of Artemisia absinthium (a standardised sample), all chromatograms were produced on both aluminum-backed TLC plates and glass-backed HPTLC plates. All chromatograms were verified and interpreted in conjunction with two experts in the field of chromatography and phytochemical analysis.

\section{Artemisia absinthium (Samples D and E)}

$10 \mathrm{ml}$ of mother tincture was concentrated to $7 \mathrm{ml}$ under reduced pressure at $35^{\circ} \mathrm{C}$. The solution was shaken with three $10 \mathrm{ml}$ portions of a mixture of $7 \mathrm{ml}$ ethyl acetate and $93 \mathrm{ml}$ of toluene and the combined organic phases were evaporated to dryness under reduced pressure. The residual was dissolved in $1 \mathrm{ml}$ of the mixture of $7 \mathrm{ml}$ ethyl acetate and $93 \mathrm{ml}$ of toluene (GHP, 2003).

Reference solution: A reference standard sample which contains the active components of Artemisia absinthium is not stipulated in the German Homoeopathic Pharmacopoeia but there is rather stipulation of expected colours of the active components. In order to mitigate this potential subjective influence a reference sample was developed and photographed by Dr E Prozesky, of Natura Laboratories, Pretoria, utilizing the same procedure, mentioned above and used for comparison against the sample plate produced. $30 \mu \mathrm{l}$ of the test solution was applied to the silica plate. The sample was developed to a distance of $100 \mathrm{~mm}$ (reduced from $150 \mathrm{~mm}$ in order to standardise all sample development distances) with a mixture of $10 \mathrm{ml}$ of anhydrous acetic acid, $10 \mathrm{ml}$ of acetone and $80 \mathrm{ml}$ of toluene. The mobile phase was allowed to evaporate, then the chromatograms were sprayed with acetic anhydride-sulphuric acid, heated to $105^{\circ} \mathrm{C}$ for $5-10$ minutes and examined in daylight within 10 minutes.

\section{Rosmarinus officinalis e foliis recentibus (Samples B, C, D and F)}

$10 \mathrm{ml}$ of mother tincture was shaken with three $10 \mathrm{ml}$ portions of hexane. The combined organic phases were filtered, evaporated to dryness under reduced pressure at $30^{\circ} \mathrm{C}$ and the residue was dissolved in $1 \mathrm{ml}$ of methanol (GHP, 2003).

Reference solution: $10 \mathrm{mg}$ of borneol, $20 \mathrm{mg}$ of bornyl acetate and $20 \mathrm{ul}$ of cineole was dissolved in $10 \mathrm{ml}$ of methanol.

$30 \mu \mathrm{l}$ of the test solution and $10 \mu \mathrm{l}$ of the reference solution was applied separately to the silica plates. All samples were developed to a distance of $100 \mathrm{~mm}$ with a mixture of $20 \mathrm{ml}$ of diisopropyl ether and $80 \mathrm{ml}$ of toluene. The mobile phase was allowed to evaporate, the chromatograms were then sprayed with anisaldehyde solution, heated at $105^{\circ} \mathrm{C}$ for $5-10$ minutes and examined in daylight within 10 minutes.

\section{Sambucus nigra (Samples A, B, D, E and F)}

$10 \mathrm{ml}$ of mother tincture was shaken with two $10 \mathrm{ml}$ portions of ethyl acetate. The combined organic phases were dried over anhydrous sodium sulphate and evaporated to dryness. The residue was dissolved in $0.5 \mathrm{ml}$ of methanol (GHP, 2003).

Reference solution: $10 \mathrm{mg}$ of each chlorogenic acid, caffeic acid and rutoside was dissolved in $10 \mathrm{ml}$ of methanol. 
$30 \mu \mathrm{l}$ of test solution and $20 \mu \mathrm{l}$ of the reference solution were applied separately to the silica plates. Each sample was developed to a distance of $100 \mathrm{~mm}$ with a mixture of $7 \mathrm{ml}$ anhydrous formica acid, $7 \mathrm{ml}$ of glacial acetic acid, $18 \mathrm{ml}$ of water and $68 \mathrm{ml}$ of ethyl acetate. The mobile phase was allowed to evaporate in a current of warm air. The chromatogram was sprayed with a $10 \mathrm{ml} / 1$ solution of diphenylboric acid aminoethyl ester in methanol and then with a $50 \mathrm{ml} / 1$ solution of macrogol 400 in methanol. The chromatogram was left for 30 minutes and examined in ultraviolet light at $365 \mathrm{~nm}$.

\section{Salvia officinalis (Samples A, B, C, D and E)}

$10 \mathrm{ml}$ of mother tincture were shaken with three $5 \mathrm{ml}$ portions of pentane. The organic phases were dried over anhydrous sodium sulphate and filtered. The filtrate was evaporated to dryness under reduced pressure and the residue was dissolved in $1 \mathrm{ml}$ of methanol (GHP, 2003).

Reference solution: $10 \mathrm{mg}$ of borneol, $20 \mathrm{mg}$ of bornyl acetate and $30 \mathrm{ul}$ of cineole was dissolved in $10 \mathrm{ml}$ of methanol.

$10 \mu \mathrm{l}$ of the test solution and $10 \mu \mathrm{l}$ of the reference solution were applied separately to the silica plates. Each sample was developed to the distance of $100 \mathrm{~mm}$ with a mixture of $20 \mathrm{ml}$ of diisopropyl ether and $80 \mathrm{ml}$ of toluene. The mobile phase were allowed to evaporate, then the chromatograms were sprayed with anisaldehyde solution, heated at $105^{\circ} \mathrm{C}$ for $5-10$ minutes and examined in daylight within 10 minutes.

\section{Results and Discussion Colour Analysis}

Colour variations of homoeopathic mother tinctures are dependent on various factors including the time of harvest, the amount of rainfall and even small differences in the manufacturing process can cause a change in the colour of the mother tincture. A high chlorophyll concentration in the plant at the time of harvest may render a tincture showing a more green colouring whereas a high flavonoid glycoside concentration will show a more yellowish colouring of the mother tincture (WHO, 2003).

Table 3.1: Colour compliance of all samples of all homoeopathic mother tinctures when compared to the standard colour stipulated in the GHP (Poor, Acceptable, Good)*

\begin{tabular}{|c|c|c|c|c|c|c|c|}
\cline { 2 - 7 } \multicolumn{1}{c|}{} & $\begin{array}{c}\text { Standard } \\
\text { GHP } \\
\text { Colour }\end{array}$ & A & B & C & D & E & F \\
\cline { 2 - 8 } & $\begin{array}{c}\text { Yellowish to } \\
\text { green brown }\end{array}$ & - & - & - & Good & Good & - \\
\hline $\begin{array}{c}\text { Arsinthium } \\
\text { officinalis } \\
\text { foliis } \\
\text { recentibus }\end{array}$ & $\begin{array}{c}\text { Yellowish to } \\
\text { red brown }\end{array}$ & - & Good & Good & Good & - & Good \\
\hline $\begin{array}{c}\text { Sambucus } \\
\text { nigra }\end{array}$ & $\begin{array}{c}\text { Brownish } \\
\text { green }\end{array}$ & Acceptable & Acceptable & - & Good & Acceptable & Good \\
\hline $\begin{array}{c}\text { Salvia } \\
\text { officinalis }\end{array}$ & $\begin{array}{c}\text { Greenish } \\
\text { brown }\end{array}$ & Good & Poor & Good & & Good & Good \\
\hline
\end{tabular}

* Poor = colour was distinctly different to GHP standard, Acceptable = colour was different from GHP standard but close enough to be considered acceptable, Good = colour matched GHP standard

\section{Thin Layer Chromatography Artemisia absinthium}

Artemisia absinthium contains three significant active constituents, which play a role in the quality of the mother tincture: artabsin, thujone and absinthin. When analyzing the standardized reference sample, Figure 3.1 (Reference), artabsin can be identified at the $R_{f} 0.53$ with a yellow orange colour, thujone at the $R_{f} 0.44$ with a dark brown colour and absinthin at the $\mathrm{R}_{\mathrm{f}} 0.39$ with a light brown colour.

After derivatization of the aluminum-backed TLC plate (Plate A) Sample E showed three less spots than Sample D, however all three active components were present, indicating no significant effect on the quality of the sample. On the glassbacked HPTLC plate (Plate B) after derivatization, Samples D and E both showed the same number of spots with the same colouring throughout as well as the presence of all three actives.

The concentration of the active components, assessed through the darker colouring of the respective spots as well as the size of the spots, was greater in Sample E than that of Sample D. Sample E was therefore selected as the sample with the greater quality when compared to Sample D. 


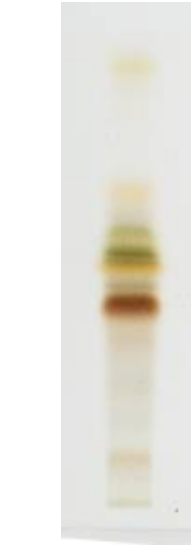

Reference

\section{(Glass)}

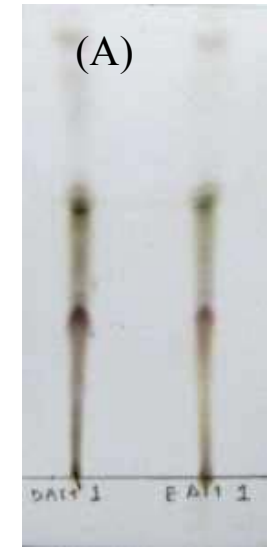

D E

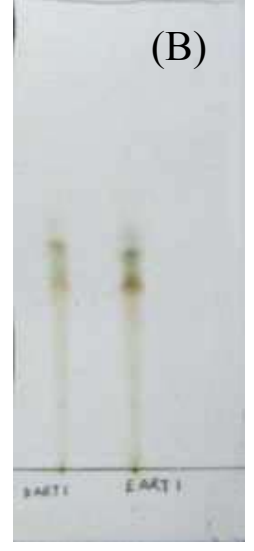

D E

Figure 3.1: Thin layer chromatograms of Artemisia absinthium

Eluent: toluene: acetone: acetic acid (80:10:10, v/v/v). Sprayed with acetic anhydride sulphuric acid solution. (a) Aluminumbacked TLC plate. (b) Glass-backed HPTLC plate

\section{Rosmarinus officinalis e foliis recentibus}

Borneol, rosmarinic acid, 1,8-cineole and bornyl acetate are the four active components essential for the medicinal properties of Rosmarinus officinalis e foliis recentibus.

On Plate A (Figure 3.2), the reference sample showed borneol at the $\mathrm{R}_{\mathrm{f}} 0.31,1,8$-cineole at the $\mathrm{R}_{\mathrm{f}} 0.34$ and bornyl acetate at the $R_{f}$ 0.75. All the samples, except Sample $C$, showed the presence of all three active components at similar $R_{f}$ values. Sample $C$ does not contain bornyl acetate at the mean $R_{f} 0.75$, therefore indicating a poorer quality of this sample when compared to the other samples.

On Plate B, Sample B, D and F contain all three active components; however Sample C did not show the presence of the bornyl acetate at the $\mathrm{R}_{\mathrm{f}} 0.76$, again indicating a poorer quality.

Figure 3.2 clearly shows the inadequate quality of Sample C, when compared to the other samples. The separation of Sample $\mathrm{C}$ is poor with a lack of components above the first active component.

Both Samples B and F have a superior quality when compared to Samples C and D. When assessing the size of the spots as well as the intensity of their colour to determine the concentration of the active components, Sample $\mathrm{F}$ had a greater concentration of borneol and rosmarinic acid whereas Sample B contained a higher concentration of 1,8-cineole and bornyl acetate. Sample F was declared as having the greatest quality.

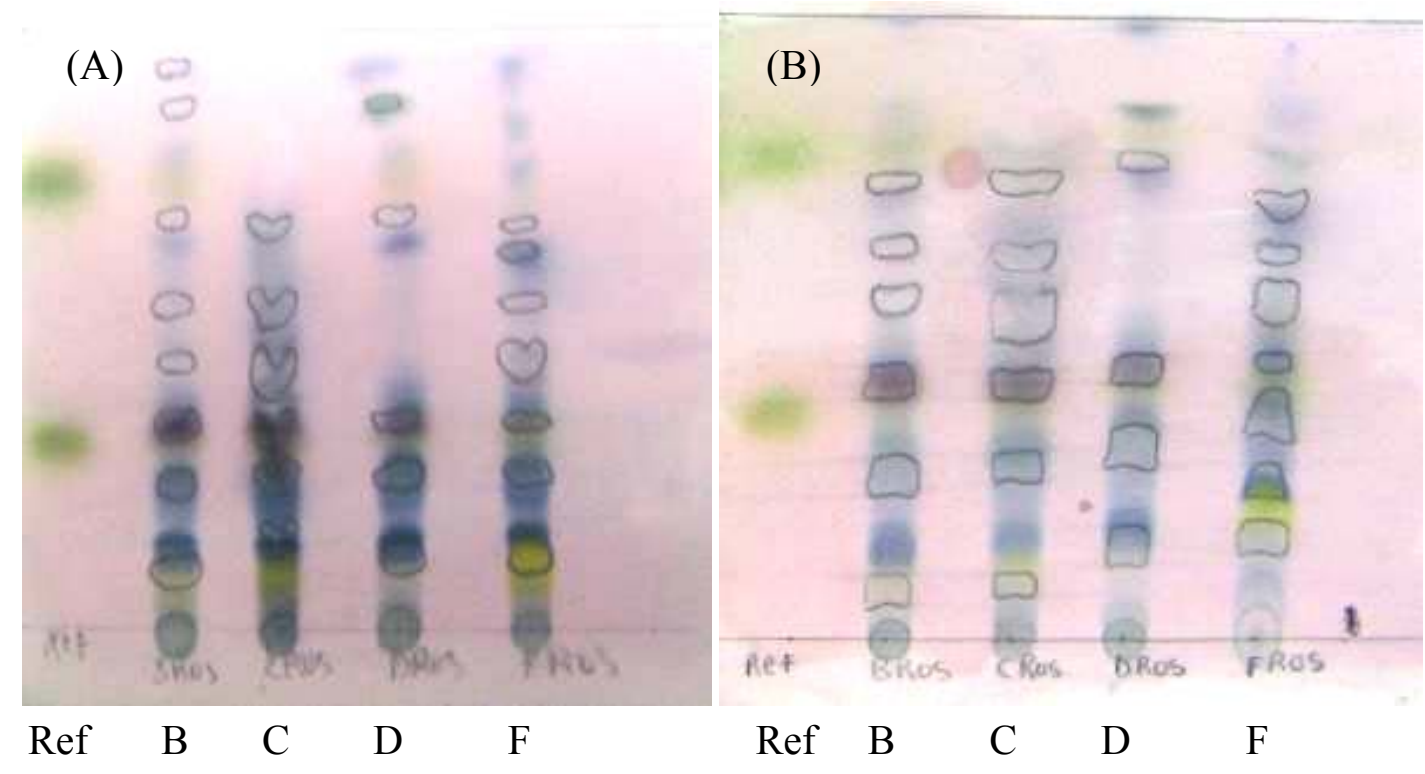

Figure 3.2: Thin layer chromatograms of Rosmarinus officinalis e foliis recentibus Eluent: diisopropyl ether: toluene $(20: 80, \mathrm{v} / \mathrm{v})$. Sprayed with anisaldehyde solution. (a) Aluminum-backed TLC plate. (b) Glass-backed HPTLC plate 


\section{Sambucus nigra}

The three spots present in the reference sample, are indicative of the active components and can be identified as rutin, chlorogenic acid and caffeic acid. On Plate A2, the aluminum-backed TLC plate; the reference sample showed the $\mathrm{R}_{\mathrm{f}}$ 0.42 for rutin, the $R_{f} 0.56$ for chlorogenic acid and the $R_{f} 0.99$ for caffeic acid. All the samples (A, B, D, E and F) showed a presence of all three actives with similar $\mathrm{R}_{\mathrm{f}}$ values.

On plate B2, the glass-backed HPTLC plate, the reference sample showed the $R_{f} 0.34$ for rutin, the $R_{f} 0.43$ for chlorogenic acid and the $\mathrm{R}_{\mathrm{f}} 0.93$ for caffeic acid. All Samples A, B, D, E and F showed the presence of rutin, however Samples $A$ and $B$ did not show a spot at the $R_{f} 0.43$, indicating that these samples did not show the presence of chlorogenic acid. For caffeic acid, Samples D, E and F did not show any spots.

UV detection for Sambucus nigra is important as the majority of components in the samples are fluorescent compounds. When assessing Figure 3.3 (Plate A1 and B1), rutin shows a dark black spot, while chlorogenic acid and caffeic acid show a white colour. Samples A and B however do show less fluorescent spots than the other samples. On comparison of Plate A1 and Plate B1, there is little difference in the separation quality of the fluorescent components between the two different types of plates.

All the samples show the presence of all three actives on the aluminum-backed TLC plate (Plate A2), yet not all active components appear on the glass-backed HPTLC plate (Plate B2). This is not indicative of a quality deficiency, but the effect of the use of a different type of plate.

Samples D, E and F appear to have a superior quality when compared to Samples A and B. When assessing the size of the spots as well as the intensity of their colour to determine the concentration of the active components, Sample F had a greater concentration of rutin and chlorogenic acid whereas Samples D and E contained a higher concentration of caffeic acid. Sample F was selected as the best sample based on its clear separation throughout both plates and the presence of all three actives.

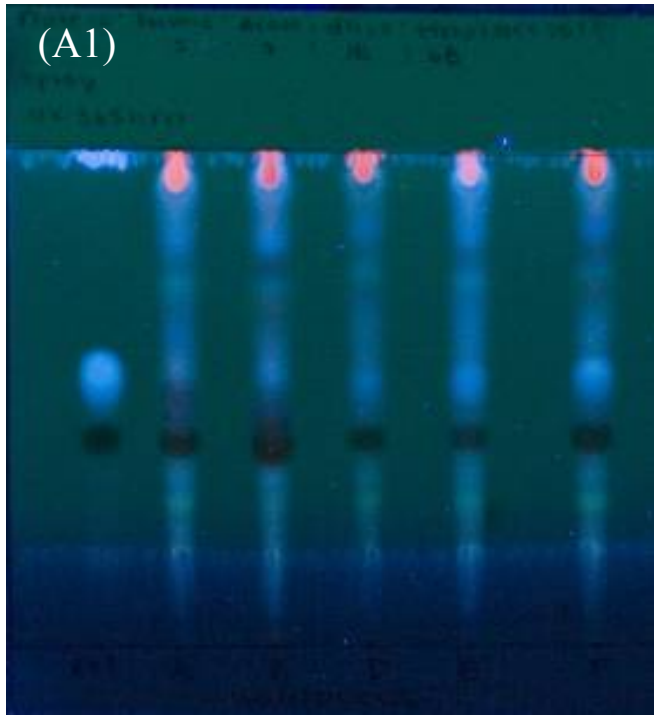

Ref A B D $\quad$ E $\quad$ F

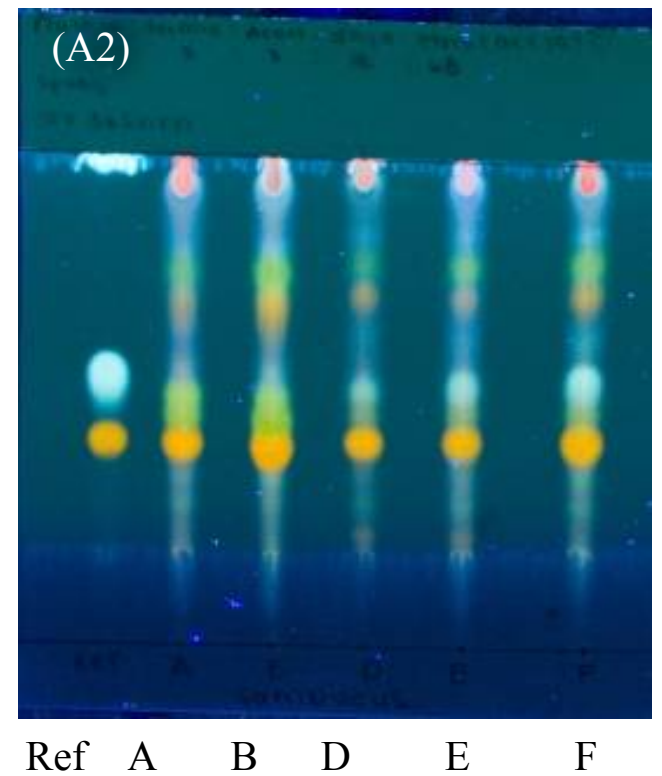

Ref A $\quad$ B $\quad$ D $\quad$ E $\quad$ F

Figure 3.3: Thin layer chromatograms of Sambucus nigra on aluminum-backed TLC plate.

Eluent: formic acid: acetic acid: distilled water: ethyl acetate $(7: 7: 18: 68, \mathrm{v} / \mathrm{v} / \mathrm{v} / \mathrm{v})$.

(a) UV 365nm. (b) Sprayed with diphenylboric acid, UV 365nm 

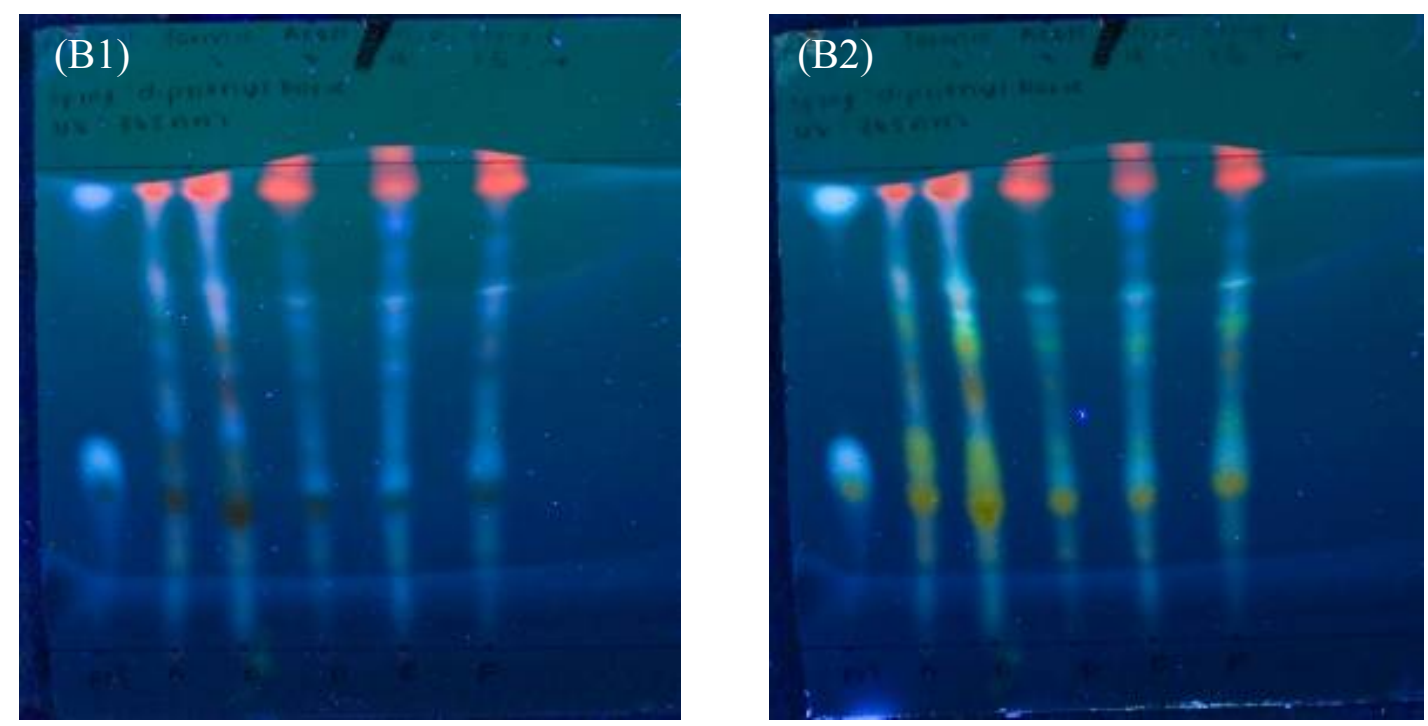

Ref A B $\quad$ D $\quad$ E $\quad F$

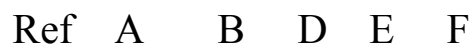

Figure 3.4: Thin layer chromatogram of Sambucus nigra on glass-backed HPTLC plate.

Eluent: formic acid: acetic acid: distilled water: ethyl acetate $(7: 7: 18: 68, \mathrm{v} / \mathrm{v} / \mathrm{v} / \mathrm{v})$.

(a) UV 365nm. (b) Sprayed with diphenylboric acid, UV 365nm

\section{Salvia officinalis}

Borneol, 1,8 cineole and bornyl acetate are the three active components essential for the medicinal properties of Salvia officinalis. On Plate A (Figure 3.5), the reference sample showed borneol at the $R_{f} 0.36,1,8$-cineole at the $R_{f} 0.39$ and bornyl acetate at the $\mathrm{R}_{\mathrm{f}}$ 0.79. Only Samples B and C showed the presence of all three active components, with Samples A, D and E lacking the presence of bornyl acetate at the $\mathrm{R}_{\mathrm{f}}$ 0.79. On Plate B, Samples C, D and E contain all three active components, with Samples A and B not showing a spot at the $\mathrm{R}_{\mathrm{f}} 0.43$ for 1,8 -cineole.

Figure 3.5 clearly shows the variation between the samples, with the presence or lack thereof of the active component, the changes of colour between the plates and the varying spot sizes. As no one sample lacks an active component in both the aluminum-backed TLC plate (Plate A) and the glass-backed HPTLC plate (Plate B), one cannot state that there is a sample with an inadequate quality. Sample $\mathrm{C}$ was, however, consistent throughout both plates, showing the presence of all three actives with a clear separation of the other components.

Both Samples C and E have a superior quality when compared to Samples A, B and D. When assessing the size of the spots as well as the intensity of their colour to determine the concentration of the active components, Sample E had a greater concentration of borneol and rosmarinic acid whereas Sample C contained a higher concentration of 1,8-cineole and bornyl acetate.
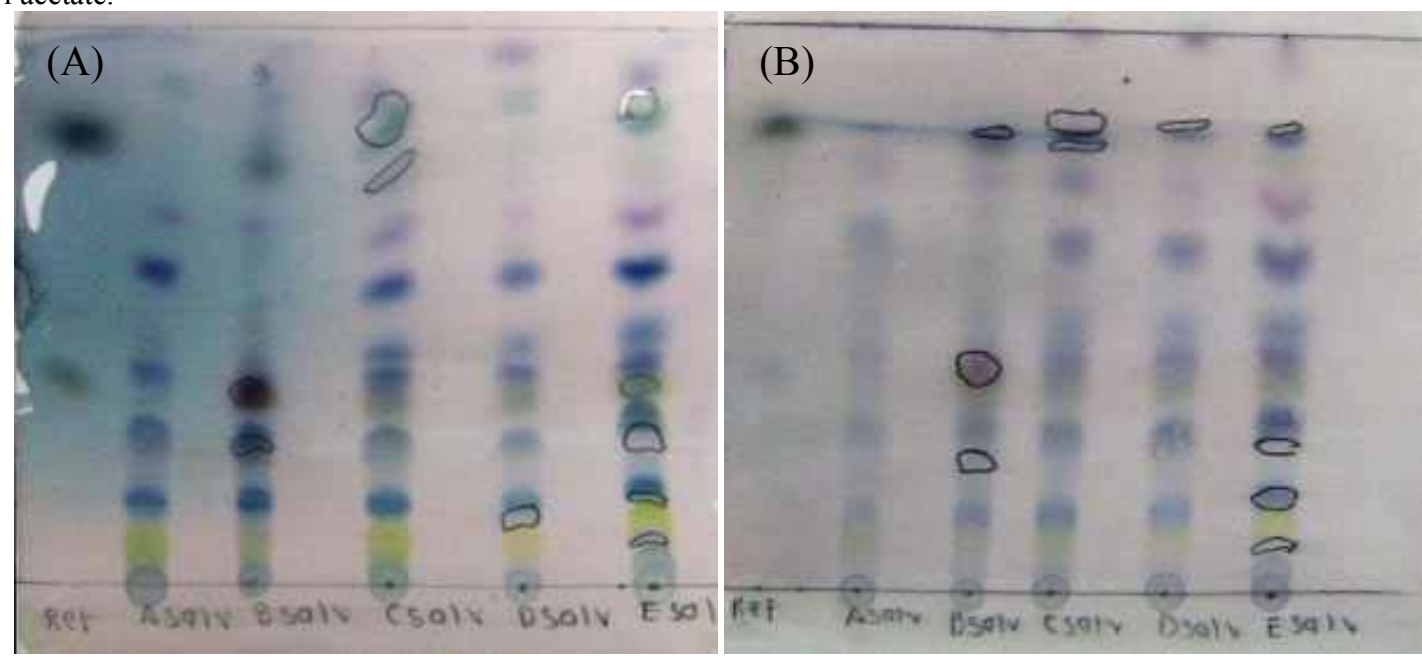

Ref A B C D E

Figure 3.5: Thin layer chromatograms of Salvia officinalis

Eluent: diisopropyl ether: toluene $(20: 80, \mathrm{v} / \mathrm{v})$. Spayed with anisaldehyde solution.

(a) Aluminum-backed TLC plate. (b) Glass-backed HPTLC plat 
Table 3.2: Summary of quality assessment of selected homoeopathic mother tinctures

\begin{tabular}{|c|c|c|c|c|c|}
\hline \multirow[b]{2}{*}{ Manufacturer } & \multirow[b]{2}{*}{ Sample } & \multicolumn{4}{|c|}{ Homoeopathic Mother Tincture Quality } \\
\hline & & $\begin{array}{c}\text { Artemisia } \\
\text { absinthium }\end{array}$ & $\begin{array}{c}\text { Rosmarinus } \\
\text { officinalis } e \text { foliis } \\
\text { recentibus }\end{array}$ & Sambucus nigra & Salvia officinalis \\
\hline \multirow{3}{*}{ Local } & $\mathrm{A}$ & $\mathrm{N} / \mathrm{A}$ & $\mathrm{N} / \mathrm{A}$ & Acceptable & Good \\
\hline & $\mathrm{B}$ & N/A & Good & Acceptable & Good \\
\hline & $\mathrm{C}$ & N/A & Poor & N/A & $\begin{array}{c}\text { Good } \\
\text { (Best) }\end{array}$ \\
\hline \multirow{3}{*}{ International } & $\mathrm{D}$ & Good & Good & Good & Good \\
\hline & $\mathrm{E}$ & $\begin{array}{c}\text { Good } \\
\text { (Best) }\end{array}$ & $\mathrm{N} / \mathrm{A}$ & Good & Good \\
\hline & $\mathrm{F}$ & N/A & $\begin{array}{l}\text { Good } \\
\text { (Best) }\end{array}$ & $\begin{array}{l}\text { Good } \\
\text { (Best) }\end{array}$ & $\mathrm{N} / \mathrm{A}$ \\
\hline
\end{tabular}

* Poor = active components not present thus not meeting minimum GHP standards, Acceptable = all active components were present and met minimum GHP standards, Good = all active components present and exceeded minimum GHP standards in terms of active component spot size and colour, Best $=$ the best quality sample

Table 3.3: Summary of overall quality performance of the local and international manufacturers

\begin{tabular}{|c|c|c|c|c|c|}
\hline \multicolumn{2}{|c|}{ Manufacturer } & \multicolumn{4}{c|}{ Quality* } \\
\cline { 3 - 6 } & 1 & Poor & Acceptable & Good & Best \\
\hline \multirow{3}{*}{ Local } & 2 & & & $\checkmark \checkmark$ & $\checkmark$ \\
& 3 & $\checkmark$ & $\checkmark$ & $\checkmark$ & $\checkmark$ \\
\hline \multirow{3}{*}{ International } & 1 & & $\checkmark$ & $\checkmark \checkmark \checkmark$ & $\checkmark$ \\
\cline { 2 - 6 } & 2 & & & $\checkmark \checkmark$ & $\checkmark$ \\
\hline
\end{tabular}

* Poor $=$ active components not present thus not meeting minimum GHP standards, Acceptable = all active components were present and met minimum GHP standards, Good = all active components present and exceeded minimum GHP standards in terms of active component spot size and colour, Best $=$ the best quality sample

\section{Conclusion}

As suggested by the experimental findings, while bearing in mind the limitations of the study with respect to numbers of homoeopathic tinctures tested, the selected internationally manufactured homoeopathic mother tinctures demonstrated a superior quality when compared to the selected locally manufactured homoeopathic mother tinctures. This indicates the need for increased regulation and quality assurance of all complementary and alternative medicines manufactured in South Africa.

\section{Acknowledgements}

Dr. Erwin Prozesky, Natura Laboratories, Pretoria, South Africa for co-supervising the research.

Prof. Bradley Williams, Department of Chemistry, University of Johannesburg, South Africa for the use of his laboratory and his assistance throughout the experimental procedure.

\section{References}

1. Banerjee, D.D. (2002). A text book of homoeopathic pharmacy. India. B Jain Publishers. p. 10.

2. German Homoeopathic Pharmacopoeia. (2003). Translated from German by Stephen Benyunes. Germany. Medpharm Scientific Publishers.

3. Gqaleni, N., Moodley, I., Kruger, H., Ntuli, A., McLeod., H. (2007) Traditional and complementary medicine. South African Health Review. Chapter 12. pp 175-188.

4. Lee, G., Vallender, M., Young., S. (2007). Setting the standards for medicine - the British pharmacopoeia. The Pharmaceutical Journal. Vol.279. pp. 566-567.

5. Pande, M., Pathak, A. (2006). Physico-chemical evaluations of homeopathic mother tincture of Mimosa pudica Linn. (lajvanti). Available from: http://www.similima.com/thesis90.html. (Accessed 11 November 2009).

6. Waksmundzka-Hajnos, M., Sherma, J., Kowalska, T. (2008). Thin layer chromatography in phytochemistry. Volume 99. USA. CRC Press. pp. 406-410, 595.

7. World Health Organization. (2009). Safety issues in the preparation of homoeopathic medicines. Spain. World Health Organization. pp. vii $-\mathrm{x}, 1-45$.

8. World Health Organization. (2003). WHO guidelines on good agricultural and collection (GACP) for medicinal plants. Geneva. World Health Organization. pp. 9-25. 